\title{
Comparison of dietary phospholipids and neutral lipids: effects on gut, liver and pancreas histology in Atlantic cod (Gadus morha L.) larvae
}

\author{
P.-A. Wold ${ }^{1,}$, , K. Hoehne-Reitan ${ }^{1}$, C.L. Cahu ${ }^{2}$, J.Z. Infante ${ }^{2}$, J. Rainuzzo ${ }^{3}$ \& E. Kjørsvik ${ }^{1}$
}

\author{
${ }^{1}$ The Norwegian University of Science and Technology, Department of Biology, Trondheim, Norway \\ ${ }^{2}$ UMR 1067 of Fish Nutrition IFREMER, Plouzané, France \\ ${ }^{3}$ SINTEF Fisheries and Aquaculture, Trondheim, Norway \\ *: Corresponding author : P.-A. Wold, email address : per-arvid.wold@bio.ntnu.no
}

\begin{abstract}
:
The aim of the present study was to compare effects of dietary n-3 highly unsaturated fatty acids (HUFA) being incorporated in the phospholipid (PL) or in the neutral lipid (NL) fraction of the larval feed, on larval growth and histology of digestive organs in Atlantic cod (Gadus morhua L.) larvae. Three isoproteic and isolipidic diets, labelled according to the percentage of $n-3$ docosahexaenoic acid and eicosapentaenoic acid contained in NL1 or in PL1 and PL3 of the diets, were fed to cod larvae from 17 days post hatching (dph) to $45 \mathrm{dph}$.

In the liver, hepatocytes and their nuclei were smaller in NL1 larvae compared with the PL larvae; the mitochondrial membrane structures were less dense and the amount of lipids observed in the liver was significantly higher in NL1 larvae compared with the PL3 larvae. The liver and gut size was related to larval size, with no differences between the larval groups. The results demonstrated that the essential fatty acids were more beneficial for cod larvae when they were incorporated in the dietary polar PL rather than in the NL, and that the n-3 HUFA requirements in cod larvae is possibly higher than that in the PL1 diet.
\end{abstract}

Keywords: $\operatorname{cod} \bullet$ diet $\bullet$ histology $\bullet$ larvae $\bullet$ lipid class $\bullet$ nutrition $\bullet$ phospholipids $\bullet$ stereology

\section{Introduction}

The commercial juvenile production of Atlantic cod (Gadus morhua) is still a challenge, much due to suboptimal nutrition during the first stages. Cod larval rearing is still largely depending on a live feed period with rotifers (Brachionus sp.) and Artemia during the early larval phase. The nutritional value of these commonly used live feed organisms is variable, and in particular the Artemia lipid composition after enrichment is rather unstable (Evjemo et al. 2001; Olsen et al., 2004). Due to high costs in live feed production, one main objective in cod larval rearing is to formulate a compound diet that can substitute live prey, in particular Artemia, as early as possible during larval development.

Controlling the diet composition, by using formulated diets, makes it possible to study the digestive mechanisms in marine fish larvae in the critical period when they start feeding exogenous diets and thereby reducing the larval age at weaning. Cahu et al. (2003a) demonstrated that complete substitution of live feed by formulated diets in marine fish larval rearing is possible when larval sea bass (Dicentrarchus labrax) were reared with compound diets only from mouth opening. So far this is not achieved with cod larvae and cod larvae fed 
formulated diets before development of the stomach have shown less growth than larvae fed rotifers and Artemia (MacQueen Leifson, 2003). A shift from rotifers to Artemia or to a formulated diet 20-30 dph is usual in cod aquaculture industry (Hamre, 2006), and Baskerville-Bridges and Kling (2000) and MacQueen Leifsson (2003) demonstrated that cod larvae can be weaned directly from rotifers to a specialized microparticulate diet without incorporating an intermediate Artemia phase, although slower growth was reported than in larvae fed Artemia. The present study is one of few early-weaning experiments performed with cod larvae where Artemia is entirely substituted by formulated diets as early as $17 \mathrm{dph}$ to investigate the effect of dietary lipid composition on larval growth and development.

Dietary lipids are the main energy source for developing fish larvae (Sargent et al. 2002), and the n-3 highly unsaturated fatty acids (HUFAs) have been identified as essential dietary components for marine fish since they cannot synthesize them de novo (Cahu and Zambonino Infante, 2001; Bell et al. 2003). Generally, marine fish larvae require docosahexaeonic acid (DHA, 22:6n-3) and eicosapentaeonic acid (EPA, 20:5n-3) (Rainuzzo et al.; 1997, Sargent et al.; 2002, Izquierdo, 2004) and the optimal level of EPA+ DHA in marine finfish larvae seem to be about 3\% of dietary dry matter (Cahu and Zambonino Infante, 2001; Sargent et al., 2002). Cod larvae do have high requirements for DHA and EPA especially in the earliest days of feeding (Hoehne, 1999; O`Brien-MacDonald et al. 2006). The use of diets with a high DHA/EPA ratio (>1.5 - 2.0) generally shows better larval survival and growth than a lower ratio (Kjørsvik et al. 2004).

Most studies determining the HUFA requirements have been conducted with live prey enriched with fish oils, which are mainly rich in triacylglycerids (TAG) (Izquierdo et al. 2000). Thus the effect of lipid classes, such as neutral lipids (NL) and phospholipids (PL) is little studied, although dietary phospholipids are essential for normal larval development. Growth, normal skeletal development and gut maturation during early development in sea bass (Dicentrarchus labrax) were more linked to the proportions of dietary PL and NL than to the total dietary lipid content (Cahu et al. 2003a and 2003b). Furthermore, Gisbert et al. (2005) concluded that sea bass larvae used DHA and EPA more efficiently from the PL fraction than from the NL fraction on basis of growth, survival, histological organization of the liver and the intestine, as well as the digestive enzyme activity. Dietary PL seem to have a marked effect on the lipid absorption and transport (Coutteau et al. 1997; Salhi et al. 1999; Izquierdo et al., 2000), and the accumulation of lipid droplets in the enterocytes (Diaz et al., 1997, Olsen 
et al. 2003, Gisbert et al. 2005) and the hepatocytes (Caballero et al. 2004, Gisbert et al. 2005) has been associated with PL deficiency, may result in steatosis (Segner et al. 1993).

Histology has shown to be a powerful tool describing tissue changes and pathology in the liver, pancreas and intestine due to different dietary compositions during nutritional studies (Olsen et al, 1999, Crespo et al. 2001; Caballero et al., 2003 and 2004; MacQueen Leifsson et al, 2003a and b; Brandsen et al., 2005, Gisbert et al., 2005; Morais et al. 2006) providing useful information about the quality of the diet. Stereology involve the opportunity to estimate the number, size and surface of any organs, cells and organelles in order to observe the ontogeny of developing organs, and is an essential tool when the number or size of units in any organ system is to be estimated. Stereological techniques based on tissue sections in microscopy (Howard and Reed, 1988), have shown to be powerful tools to quantify the characteristics of the development of the liver in turbot larvae (Segner and Witt, 1990; Segner et al., 1994), pathological effects due to dietary lipid composition in enterocytes of Arctic char Salvelinus alpinus L. (Olsen et al., 1999) and sea bream (Caballero et al., 2003), and lipid accumulation in hepatocytes of sea bream (Caballero et al. 2004).

The aim of the present study was to evaluate the effect of lipid classes (PL vs. NL) and the level of n-3 HUFA in the diet on larval growth, survival and the histological development of the intestine, liver and pancreas in cod larvae. The experimental design was based on cod larvae fed isolipidic and isoproteic microdiets from $17 \mathrm{dph}$ until 45 days post hatch. Liver and pancreas histology was studied by light- and electron microscope. To evaluate the effect of nutritional status on larval development stereological techniques were used to estimate accumulation of lipids in liver and intestine and size of organs, cells, nuclei and mitochondria.

\section{Material and methods}

\section{Experimental design}

Atlantic cod eggs were obtained two days before hatching. Eggs were disinfected in glutaraldehyde in seawater (0.4 g/l) for 10 minutes (Salvesen and Vadstein, 1995) and incubated at a stocking density of 150 eggs/l in nine 160 l cone bottomed black tanks in darkness at $7.5^{\circ} \mathrm{C}$ (salinity $34 \mathrm{ppt}$ ). Each dietary treatment was run in three replicate tanks. 
After hatching, light was turned on (24h- $40 \mathrm{~W}$ bulbs) and the temperature was gradually increased from 8 to $12^{\circ} \mathrm{C}$ between 1 and $6 \mathrm{dph}$, and then kept constant at $12^{\circ} \mathrm{C} \pm 0.2^{\circ} \mathrm{C}$. Water exchange was gradually increased from $0.1 \mathrm{l} / \mathrm{min}$ at hatching to $0.9 \mathrm{l} / \mathrm{min}$ from $30 \mathrm{dph}$. Larval rearing lasted up to $45 \mathrm{dph}$. Larval tanks were cleaned every second day from 1-17 dph and dead larvae were removed and counted daily from $17 \mathrm{dph}$ onwards.

\section{Live feed enrichment and larval feeding}

The larvae were fed rotifers (Brachionus. Plicatiltis “Nevada”, Gomez et al., 2002), longterm enriched with the marine emulsion Marol E provided by Sintef Fisheries and Aquaculture (Trondheim, Norway) (Rainuzzo unpubl.). Cod larvae were fed rotifers three times every day from $3 \mathrm{dph}$. Feed density was 3000-5000 ind/l until $4 \mathrm{dph}$, and then increased to 5000-7000 ind/l from $5 \mathrm{dph}$. Algal paste (Nannochloropsis sp., Reed mariculture, USA) was added from $2 \mathrm{dph}$ until the end of the rotifer phase in a concentration of $2 \mathrm{mg} \mathrm{C} / \mathrm{l}$ one to three times per day. From 17 to 24 dph there was an overlap between rotifers and formulated diets with a gradually reduction in the amounts of rotifers. From 24 dph cod larvae were fed formulated diets exclusively.

Small amounts of the formulated diets were fed manually to the larvae ( $0.15 \mathrm{~g} \mathrm{x} 10)$ on day 17 to start weaning. On $18 \mathrm{dph}, 3 \mathrm{~g} /$ day of formulated diets were added using continuous automatic belt feeders, gradually increasing the amount of feed added per day to each tank to $10 \mathrm{~g}$ from $31 \mathrm{dph}$. A pellet size of $<200 \mu \mathrm{m}$ was used from 17 to $30 \mathrm{dph}$ with an increase to $200-400 \mu \mathrm{m}$ from $30 \mathrm{dph}$. An overlap using a mixture of both pellets sizes was conducted from 30 to $36 \mathrm{dph}$.

\section{Formulated diets}

Three isoproteic and isolipidic diets, which varied in their lipid class composition, PL vs. NL, were used (Table 1). The lipid composition differed by the amount of cod liver oil, marine lecithin and soybean lecithin added. PL3 and PL1 comprised a mixture of marine and soybean lecithin as only source of lipids. The phospholipids were incorporated in two different levels and in inverse relationship into the two different diets. NL1 contained only soybean lecithin as PL source and marine TAG (cod liver oil). These differences resulted in a proximate composition with gradually decreasing levels of DHA and EPA in the dietary phospholipid (PL3 $>$ PL1 $>$ NL1) fraction and increasing levels in total dietary neutral lipid (PL3<PL1<NL1). All diets contained 51\% defatted fish meal and 14\% hydrolyzed fish meal (CPSP), 8\% 
vitamin mixture, $4 \%$ mineral mixture and $2 \%$ of betain. The total lipid content in all diets was 21\%. The diets were manufactured by IFREMER (France) according to Gisbert et al. (2005).

\section{Tissue processing for stereology}

All larvae were anaesthetised with Metacainum (Tamro 257675) in seawater and rinsed in distilled water before further treatment. 30 larvae from each dietary treatment were randomly sampled on 45 dph. Larvae were fixed in glutaraldehyde (2.5 \%) and paraformaldehyde (2.5 \%) in cacodylate buffer (0.08 M, pH 7.4). Subsequently, 5 out of the 30 larvae from each treatment were randomly picked and the larval intestine and liver was dissected out. Samples were washed in cacodylate buffer (300-320 mOsm, pH 7.4) and postfixed for $1.5 \mathrm{~h}$ in osmium tetroxide and imidazol buffer ( $\mathrm{pH}$ 7.5). Thereafter, the intestines and livers were rewashed in distilled water and stained in 1.5\% uranyle acetate, dehydrated in different ethanol concentrations and embedded in Epon.

Sectioning was performed with a Leica Reichert Ultracut microtome (Leica Microsystems, Germany). The intestine was divided into 7 segments (Figure 1). The first section made was randomly chosen from the first segment in a systematic random sampling scheme as described in Mayhew (1991) where the position of the first section determines the position of all other section in the sample (distance d, Figure 1). Each section contained 1-3 gut regions denoted by letters according to their position in the midgut (Figure 1). For each section, semi-thin and ultra-thin sections were mounted. The same procedure was followed in respect to the liver. The number of sections and/or regions used for stereology was decided by a pre-calculation process, in which the lowest number of sections/regions that affected the total estimate less than $10 \%$ was chosen.

Semi thin sections (1 $1 \mu \mathrm{m}$ thickness) were stained with toloudine blue and basic fucsin. Ultra thin sections (70 nm thickness) were transferred to copper grids and contrasted with lead citrate. A Zeiss Axioskop 2 Plus- light microscope (Zeiss Inc., Germany) and a Jeol JEM1011 transmission electron microscope (Jeol Ltd., Japan) at an accelerating voltage (at $80 \mathrm{kV}$ ) were used for tissue examination. All morphometric analysis was performed on the software CAST 2 (Olympus Denmark, 2000). It was assumed that shrinkage was equal in all samples. 


\section{Liver and intestinal size}

Liver and intestinal volume was estimated by using the Cavalieri method (Gundersen et al. 1988, Mayhew 1991). A point grid was located on all semi thin sections of each individual with a density ensuring at least 200 points to hit the total area of the organ. Each point was connected to a given area and the total volume was calculated using the formula:

$$
\mathrm{V}_{(\text {obj })}=\mathrm{t} \cdot \mathrm{a} / \mathrm{p} \cdot \Sigma \mathrm{p} \quad(\text { equation } 1)
$$

where $V_{(o b j)}$ is the volume of the object, $t$ is the distance between sections (in $\mu \mathrm{m}$ ), $a / p$ is the area connected to each point and $\Sigma$ p is the total sum of points hitting enterocytes.

\section{Hepatocyte size}

The hepatocyte size was calculated indirectly from the numerical density of the enterocyte nuclei. The number of nuclei was calculated according to the formula of Weibel et al. (1969) used for the determination of the numerical density of hepatocyte nuclei $\left(\mathrm{N}_{\mathrm{V}}\right)$ :

$$
N_{V}=\frac{1}{\beta_{i}} X \frac{N_{A n}^{3 / 2}}{V_{V n}^{1 / 2}}
$$

where $\mathrm{N}_{\mathrm{An}}$ is the number of counted nuclear profiles divided by the test area, $\mathrm{V}_{\mathrm{Vn}}$ is the part of the test area covered by the nuclei and $\beta$ is a shape dependent coefficient (Weibel and Gomez, 1962). Enterocyte volume was then calculated dividing the midgut volume by the numerical nuclei density.

\section{Nuclei size}

Nuclear volume in enterocytes, hepatocytes and the pancreas was determined by using the nucleator (Howard and Reed, 1998) on semi-thin sections (magnification 1600X). A minimum of 200 nuclei distributed in each organ were measured. A point was marked in the nucleoli and CAST created two randomly orientated lines crossing the border of the nucleus. By measuring the length of these lines inside the nucleoli, a volume $\left(V_{\text {nuc }}\right)$ was estimated by using the formula 


$$
V_{\text {пис }}=\frac{4 \pi}{3 \cdot n} \sum_{i=1}^{n} l_{n .1}^{3} \quad \text { (equation 3) }
$$

where $l_{n}$ refers to the distances from the sampling point within the nucleolus to the edge of the particle and $\mathrm{n}$ is the number of measurements.

\section{Mitochondrial size}

Mitochondrial volume in the intestine, liver and pancreas was estimated by the point sample intercepts method described by Howard and Reed (1998). An isotropic line grid, containing points, were oriented on the micrographs. When a point was hitting a mitochondrion the intercept of the line was measured and the mitochondrial volume was estimated by the equation:

$$
\left.V_{m i t}=\frac{\pi}{3 \cdot n} \sum_{i=1}^{n} l_{n .1}^{3} \quad \text { (equation } 4\right)
$$

where $V_{\text {mit }}$ is the mitochondrial volume, $\mathrm{n}$ is the number of measurements and $\mathrm{l}$ is the length of the isotropic lines intersecting the mitochondria.

\section{Volume fractions}

Volume fractions of lipid (intestine and liver), glycogen (liver) and zymogene granulae (pancreas) were estimated using 5-6 tissue regions per larvae.

A uniform frame grid was used, hitting each micrograph with 4-6 frames. A point grid was then placed in the counting frames with a density of 70-77 points per frame. Counts were made of the numbers of points hitting profiles of the mitochondria. The ratio of these point totals $\left(\sum \mathrm{P}_{\text {struc }} / \sum \mathrm{P}_{\text {frame }}\right)$ from all micrographs affords an unbiased estimate of the fraction of pancreatic tissue occupied by zymogens $\left(\mathrm{V}_{\text {struc }} / \mathrm{V}_{\text {frame }}\right)$ in that larva (See Gundersen et al., 1988). 


\section{Statistics}

Regression analysis was performed to monitor correlation between data obtained by stereological techniques and cod standard length. Data were tested for homogeneity of variances using a Levene test. To compare means, the group data were statistically tested using one-way ANOVA followed by a Student-Newman-Keuls-Test for more than two means. To compare two means a Student`s t-test was performed. In cases were parametric tests were not applicable; a non parametric Mann-Whitney-U-test was used. 5 \% level of confidence was used.

\section{Results}

At the end of the experiment (45 dph) the PL3- and PL1-larvae were significantly larger than the NL1-larvae according to average dry weight (Table 2). Between 35 and 45 dph PL1-larvae showed a higher, but not significantly different, daily weight increase (DWI) than in the other treatments. No significant differences were found between larval standard length and dietary treatment, although PL3- and PL1- larvae were longer then NL1-larvae. Survival during the dry feed period did not differ significantly between treatments on $45 \mathrm{dph}$, being $12.2 \pm 0.5 \%$ for PL3-larvae, $12.8 \pm 3.5$ for PL1-larvae and $15.7 \pm 4.5$ for NL1-larvae.

There was a positive sigmoid relation between the larval standard length and both intestinal length and volume for all larvae (Figure 2A and 2B). Average enterocyte nucleus size was largest in PL1-larvae, and was 21 \% larger than the in PL3-larvae which had the smallest nuclei. However, differences were not significant (Table 3). In respect to mitochondrial size, PL1-larvae possessed larger mitochondria and NL1-larvae possessed the smallest mitochondria although differences were not significant (Table 3).

Ingested food was clearly broken down and absorbed. In enterocytes lipid vacuolisation was observed apically in fore- and midgut (Figure 3A). Lipids were always observed in only one to two regions (from a to $\mathrm{n}$ in Figure 1) per larvae. The enterocytes were highly vacuolised in these regions, and lipid vacuoles were not related only to regions containing food particles (Figure 3B). Overall, the total lipid vacuolisation in enterocytes was low in all dietary treatments. PL3-larvae showed the highest degree of total epithelium lipid vacuolisation (1.02 \%) (Table 3). 
Liver size was not significantly different between dietary treatments, although it tended to be smaller in larvae fed the NL1 diet than the PL diets (Table 4). A positive linear regression was found between larval liver volume and standard length (Figure 4A). The numbers of hepatocytes were positively related to the liver size (Figure 4B). The total number of hepatocytes in the liver did not differ significantly between treatments (Table 4). Hepatocyte size was significantly larger in PL3- and PL1-larvae compared with the NL1larvae, being17 and $13 \%$ bigger (Table 4). The hepatocyte nucleus size was significantly smaller in NL1-larvae than in the PL-larvae, and hepatocyte nuclei in the Pl3-larvae were 18 \% larger the in NL1-larvae. No correlation between hepatocyte nuclei size and larval length was found.

Liver mitochondria in PL3- and PL1-larvae were more electron dense than in NL1-larvae, as the mitochondria in NL1-larvae contained an open intermembranous matrix (Figure 5A and B). Volume estimates showed that NL1-mitochondria in average were approximately $25 \%$ bigger in NL1-larvae than in the PL3- and PL1-larvae (Table 4), although differences were not significant.

Glycogen was rarely observed in any dietary treatment (volume fraction constituting approximately $1 \%$ of the total hepatic tissue, Table 4). Lipid droplets were observed in all livers analyzed and with the exception of PL3-larvae, the liver contained more lipid than glycogen. In contrast to intestine, an increasing lipid accumulation in hepatocytes with increasing levels of dietary neutral lipids was observed (Table 4). Lipid volume fraction in NL1-larvae was significantly higher than in PL3-larvae (3 times), and was 2 times higher than in PL1-larvae (Table 4).

Pancreatic tissue was observed as a "diffuse” organ, spread between the anterior parts of the intestine (localised in 1 to 3 semi-thin sections per larvae). Micrographs of the pancreas revealed zymogene granulae in all dietary treatments (Figure 6), and the volume fraction was similar for all diets (Table 5).

Pancreatic nuclei size was largest in PL1-larvae, but was not significantly different from than nuclei size in larvae from the other groups (Table 5). A higher mitochondrial volume fraction was observed in pancreas in larvae fed the PL1 diet than in larvae fed the PL3 and the NL1, which was caused by slightly bigger mitochondrial size (Table 5).

Comparison of organelle estimates within the same dietary treatment showed that the nucleus volume was significantly smaller in the pancreatic tissue than in both the liver and intestine 
(Figure 7A). Enterocyte nucleus size was similar for larvae from all treatments. No significant difference between nucleus size of enterocytes and liver was found for Pl-larvae, but liver nucleus size was significantly smaller then enterocyte nucleus size in the NL1-larvae. By comparing mitochondrial sizes in different organs (Figure 7B), the enterocyte mitochondria were always significantly smaller than in other organs. Liver mitochondria were larger than in the pancreas for the NL1-larvae, but this was not the case for the PL-larvae (not significantly different).

\section{Discussion}

All microdiets used in the present study supported positive larval growth and development in cod. The larval growth rate was lower than has been obtained using live feed (Wold et al., submitted), but was comparable to other early weaning trials with cod (Baskerville-Bridges and Kling, 2000, Høvde et al., submitted). The histology showed that the diets were ingested and digested by the cod larvae. DHA and EPA seemed to be more beneficial to larval growth and development when incorporated in the polar lipid fraction (PL) than in the neutral lipid (NL) fraction, as demonstrated by higher average dry weight and standard length of PL3- and PL1-larvae at the end of the experiment. Dietary marine phospholipids also had a beneficial effect on the ossification process of neural arches, haemal arches and vertebrae (Kjørsvik et al. submitted). Likewise, the establishment of an efficient brush border digestion measured as the activity of the enzyme alkaline phosphatase occurred more rapidly in larvae fed the PL3 and PL1-diets, suggesting that marine phospholipids have a beneficial effect of the maturation of the digestive system (Wold et al., in press).

The more efficient use of DHA and EPA supplied in the PL fraction of the diet might be related to the ability of young larvae to better modulate phospholipase $\mathrm{A}_{2}$ expression than that of lipase, suggesting a more efficient capacity to assimilate PL than NL as showed in sea bass larvae (Cahu et al., 2003a). However, the two different levels of marine phospholipids did not affect larval size, and PL3- and PL1- larvae were of equal size at the end of the experiment. This was in contrast to findings in sea bass larvae which showed significant differences in size between larvae fed the PL3-and PL1 diets (Gisbert et al. 2005), suggesting that cod larvae might have different requirements than sea bass larvae. However, the cod larval phospholipid requirements are not yet established. 
Larvae fed the PL3 and PL1-diets obtained slightly larger livers and intestines than NL1larvae. A dietary effect on liver volume has previously been reported in common carp where larvae fed PL-deficient diets had smaller liver volume and smaller liver nuclei than larvae fed PL-supplemented diets (Fontagnè et al., 1998). In the present study liver volume and intestinal length were positively related to larval size, indicating that these differences were rather caused by different growth rates than by dietary composition per se. Liver size was also reflected by hepatocytes size, meaning that larger livers contained the largest hepatocytes. This was in accordance with other findings, showing that liver size in developing cod larvae increased as a function of larval standard length between 2 and 39 dph (Høvde et al. submitted.). Histological studies have also shown that larval intestinal volume is more related to larval size (standard length) rather than dietary treatment (Wold et al., submitted).

Hepatocyte nucleus size was significantly smaller in larvae fed the NL1-diet than in the other treatments. NL1-larvae were the only group demonstrating significantly smaller nuclei in the liver than in the intestine, and these larvae also had very different hepatocyte mitochondrial structure. We therefore conclude that the NL1- diet had a negative effect on the liver structure. We found the liver to be more affected by dietary composition than the gut and the pancreas, and that the liver nuclei and mitochondria seemed to be very sensitive parameters for cod larval nutritional status.

Hepatocyte nuclei are shown to be affected by larval nutritional status and growth rates. A recent study in cod larvae showed that the hepatocyte nucleus volume was approximately 20 \% lower when larvae were fed a formulated diet (similar to PL3) from 25 to $30 \mathrm{dph}$, compared to the hepatocyte nucleus in larvae fed enriched Artemia (Høvde et al. submitted). The larvae fed Artemia also grew twice as fast as the larvae fed the formulated diet. In newly hatched larvae of pejerry (Odotesthes bonariensis) the nuclei volumes were constant during ontogeny provided that larvae were sufficiently fed. Nuclei volume decreased rapidly during starvation and was constant in fed larvae (Strüssman and Takashima, 1990). The hepatocyte nuclei volume decreased more rapidly during higher temperatures, which indicates that such changes in nuclei volume are connected to metabolic activity and growth.

Increasing hepatocyte nuclei volumes might be attributed to higher exchange rates between the nucleus and the cytoplasm and thereby denoting higher metabolic activity (Ghadially, 1997). The liver has an important function in the intermediate metabolism of proteins, 
carbohydrates and lipids (Hoehne-Reitan and Kjørsvik, 2004) and it is therefore likely that liver metabolic activity is higher during periods associated with rapid energy transfer.

Hepatocyte mitochondria were larger than gut and pancreatic mitochondria only in NL1larvae. PL3- and PL1- hepatocyte mitochondria had a denser intermembranous matrix than the NL1- hepatocytes. Differences in membranes structure was not observed in pancreatic and intestinal mitochondria between larvae from the different groups.

Hepatocyte mitochondrial size and structure have been used as indicators of nutritional status in fish larvae. Large swollen mitochondria in hepatocytes were described as a sign of starvation or malnutrition in fish larvae caused by autolytic bile emptied into the liver (Diaz et al., 1998, Høvde et al., submitted), and enterocytes when turbot larvae were fed diets containing vegetable lipid sources (MacQueen Leifson et al., 2003a). In the present study, mitochondrial size was slightly elevated, and typical multilamellar bodies commonly observed in swollen mitochondria (Diaz et al., 1998), were not present. We can therefore assume that the effects from the NL1-diet on mitochondria indicated a physiological stress, but were not severely pathological.

Lipid droplets were observed in all livers analyzed, and there were significantly more lipids in larvae fed the NL1-diet. Segner and Witt (1990) observed increased lipid volume fractions in turbot larvae during weaning to a formulated diet. The authors concluded that lipid accumulation was caused by a disturbance in the hepatocellular lipid transfer and metabolism during weaning to formulated diets. When gilthead sea bream larvae were fed NL or PL of marine origin, rich in n-3 HUFA, feesing with marine PL markedly reduced lipid accumulation (Salhi et al., 1999). An accumulation of lipid vacuoles in hepatocytes was observed, denoting good absorption of dietary NL, but also a reduced lipid transport compared to those fed marine PL. Salhi et al. (1999) found a higher larval lipid content due to accumulation of NL and cholesterol esters in larvae fed marine NL, whereas relative proportions of phosphatidylcholine and phosphatidylethanolamine were higher and richer in n-3 HUFA in larvae fed marine PL. Our results on cod also demonstrate that fatty acids from PL are more efficiently incorporated into larval tissue than fatty acids from dietary NL. This was also found in sea bass, where the levels of lipid accumulation in the liver of larvae fed high levels of n-3 HUFAs in the NL-fraction were higher than those fed similar or higher lipid levels in the PL-fraction (Gisbert et al. 2005). Lipd storage in cod larval liver seem generally 
to be very low (Høvde et al. submitted). Levels of lipid droplets in cod livers in the present study were too low to affect hepatocyte size, in contrast to observations in sea bass larvae fed similar diets (Gisbert et al. 2005), indicating effects caused by dietary lipids on liver metabolism in cod. In adult cod the lipid content can contribute $50-60 \%$ of the hepatic tissue (Lie et al. 1986), and the low lipid volume fractions in larval livers suggested that deposition of lipids is not important for cod until after metamorphosis.

Glycogen content in the cod larvae was not affected by dietary treatment. Glycogen seems to be the preferred storage form for energy in cod larvae. The storage of glycogen has been associated with DWI > 10\%, and cod larvae seem to prioritize rapid growth over energy storage (Høvde et al. submitted). In the present study, observed glycogen content was less than observed by Høvde et al. (submitted), and the DWI was higher than $10 \%$ in all treatments, suggesting that larval energy stores might be affected also by other factors than growth rates.

In the present study, dietary composition did not have any effect on lipid absorption, transport and accumulation of lipid droplets in cod larval enterocytes. Lipid accumulation in enterocytes in the fore- and midgut was observed in few regions of the intestine, and lipid accumulation in enterocytes was not restricted to regions were the formulated diets were present. Low dietary phospholipid levels have previously led to accumulation of large lipid droplets in enterocytes (Fontagnè et al. 1998; Izquierdo et al., 2000; Olsen et al. 2003). Accumulation of lipid vacuoles in the basal zone of the enterocytes caused by feeding diets without lechitin supplementation in gilthead sea bream disappeared when $0.1 \%$ phosphatidylcholine (PC) was added regardless of its origin (squid or soybean) (Izquierdo et al., 2000). In the present study, overall lipid accumulation in enterocytes were low in all dietary treatments and might be contributed to that all diets contained sufficient amounts of phospholipids to facilitate lipid transport in enterocytes. Diets containing more then $2 \%$ phospholipids were reported to markedly reduce lipid accumulation in larval gilthead sea bream enterocytes (Izquierdo et al., 2000). On the contrary, when gilthead sea bream larvae were fed TG of marine origin, rich in HUFAs, it was observed an accumulation of lipid vacuoles in the basal zone of enterocytes, denoting reduced lipid transport to peripheral tissues (Salhi et al., 1999). Nevertheless, it can not be excluded that dietary phospholipid composition may affect lipid accumulation in cod larval enterocytes during the earlier phases of development when the digestive system is less developed. 
In 45-days-old cod larvae the pancreas was developing towards the so called pancreas diffusum, being spread along the walls of the intestine and other organs. The larval exocrine pancreas is at hatching most commonly a distinct organ and appears histological differentiated at mouth opening in several species (Kjørsvik and Reiersen, 1992, Morrison, 1993, Segner et al. 1994, Ribeiro et al. 1999, Zambonino Infante and Cahu, 2001). A functional exocrine pancreas is characterized by differentiated organ morphology, including developed excretory ducts and the presence of zymogen granulae with the presence of all major digestive enzymes (Hoehne-Reitan and Kjørsvik, 2004). Zymogen granules were observed in all dietary treatments and in equal volume fractions. Pancreatic tissue seemed normal and no signs of pathology were observed in any treatment. Pancreatic degeneration is assumed to be one of the most reliable histological indices of poor nutritional conditions in common dentex (Dentex dentex L.) larvae, showing degeneration and disarray of the acinus structure in poorly fed larvae (Crespo et al. 2001). Cod larval pancreas histology was more difficult to evaluate by stereological methods than the intestine and liver in this study, due to its indistinct shape and the difficulty of making a reliable sampling scheme of sections.

In conclusion, larval growth and organ development showed that the lipid class in which DHA and EPA were supplied in the diet was determining for Atlantic cod larval development. Cod larvae were using DHA and EPA more efficiently when these essential fatty acids were present in the PL fraction of the diets rather than the NL fraction as demonstrated by larger larvae and more developed digestive organs. Hepatocyte cell and nucleus size, as well as mitochondrion structure were significantly affected by the different diets, suggesting more physiological stress in NL1-larvae compared to the PL-larvae, in addition to lower larval growth. Different dietary treatments did not result in severe pathological histological findings in the liver, intestine and pancreas. However, a more comprehensive gradient experiment is necessary to evaluate the optimal lipid composition of an early weaning diet for this species.

In cod larvae, nucleus and mitochondrial size were significantly different between the different digestive organs and hepatocyte nuclei and mitochondria were especially sensitive to dietary induced effects. On the basis of results from this experiment, it may be recommended for future stereological studies of dietary effects in cod larvae, to focus on liver structure, and rather put effort in optimizing the efficiency of stereological studies by analyzing mire 
individuals rather than doing more comprehensive work on fewer individuals (Gundersen and Østerby, 1981).

\section{Acknowledgements}

The corresponding author will thank the Norwegian University of Science and Technology for funding his $\mathrm{PhD}$-work for letting me use their research facilities. The authors also thank the Norwegian Research Council for funding through the research projects "CodTech” (NRC 153422/120) and "Effects of phospholipid supplement in microdiets during co-feeding of marine fish larvae” (NRC 142025/120).

The authors will also thank chief engineer Tora Bardal at the department of biology (NTNU) for great help and support during the histological studies. 


\section{References}

Baskerville-Bridges, B. and Kling, L.J. 2000. Early weaning of Atlantic cod (Gadus morhua) larvae onto a microparticulate diet. Aquaculture 189:109-117.

Bell, J. G., McEvoy, L. A., Estevez, A., Shields, R. J. and Sargent, J. R., 2003. Optimising lipid nutrition in first-feeding flatfish larvae. Aquaculture 227, 203-220.

Brandsen, M. P., Cobcroft, J. M., Battaglene, S. C., Morehead, D. T., Dunstan, G. A., Nicholds, P. D., and Kolkovski, S. 2005. Dietary 22:6n-3 alters gut and liver structure and behaviour in larval striped trumpeter (Latris lineate). Aquaculture 248, 275-285.

Caballero, M.J., Izquierdo, M. S., Kjørsvik, E., Montero, D., Socorro, J., Fernández, A. J., and Rosenlund, G. 2003. Morphological aspects of intestinal cells from gilthead seabream (Sparus aurata) fed diets containing different lipid sources. Aquaculture 225, 325340.

Caballero, M. J., Izquierdo, M. S., Kjørsvik, E., Fernàndez, A. J., and Rosenlund, G. 2004. Histological alterations in the liver of sea bream, Sparus aurata L., caused by short- or long-term feeding with vegetable oils. Recovery of normal morphology after feeding fish oil as the sole lipid source. Journal of Fish Diseases 27, 531-541.

Cahu, C. and Zambonino Infante, J., 2001. Substitution of live food by formulated diets in marine fish larvae. Aquaculture 200,162-180.

Cahu, C. L., Zambonino Infante, J. L. and Barbosa, V., 2003a. Effect of dietary phospholipid level and phospholipid :neutral lipid value on the development of sea bass (Dicentrarchus labrax) larvae fed a compound diet. British Journal of Nutrition 90, 21-28.

Cahu, C. L., Zambonino Infante, J. L. and Takeuchi, T. V., 2003b. Nutritional components affecting skeletal development in fish larvae. Aquaculture 227, 245-258. 
Cotteau, P., Geurden, I., Camara, M. R., Bergot, P., and Sorgeloos, P. 1997. Review on the dietary effects of phospholipids in fish and crustacean larviculture. Aquaculture 155, 149164.

Crespo, S., Marìn de Mateo, M., Santamarìa, C. A., Sala, R., Grau, A., and Pastor, E. 2001. Histopathological observations during larval rearing of common dentex Dentex dentex L. (Sparidae). Aquaculture 192, 121-132.

Diaz, J. P., Guyot, E., Vigier, S., and Connes, R. 1997. First events in lipid absorption during post-embryonic development of the anterior intestine in gilt-head sea bream. Journal of fish biology 51, 180-192.

Diaz, J. P., Mani-Ponset, L., Guyot, E., and Connes, R. 1998. Hepatic cholestasis during the post-embryonic development of fish larvae. The Journal of Experimentsl Zoology 280, 277-287.

Evjemo, J. O., Danielsen, T. L., and Olsen, Y. 2001. Losses of lipid, protein and n-3 fatty acids in enriched Artemia Franciscana starved at different temperatures. Aquaculture 193: 65-80.

Fontagnè, S., Geurden, I., Escraffe, A- M., and Bergot, P. 1998. Histological changes induced by dietary phospholipids in intestine and liver of common carp (Cyprinus carpio L.) larvae. Aquaculture 161, 231-223.

Ghadially, F. N. 1997. Ultrastructural pathology of the cell and matrix. Volume $1.4^{\text {th }}$ ed. Butterworth-Heinemann, MA, USA. pp 4

Gisbert, E., Villeneuve, L., Zambonino Infante, J. L., Quazuguel, P. and Cahu, C. L., 2005.

Dietary phospholipids are more efficient than neutral lipids for long-chain polyunsaturated fatty acid supply in European sea bass Dicentrarchus labrax larval development. Lipids 40(6), 1-11. 
Gomez, A, Serra, M., Carvalho, G. R. and Lunt, D. H. 2002. Spectation in ancient cryptic species complexes: evidende from the molecular phylogeny of Brachionus plicatilis (Rotifera). Evolution 56 (7), 1431-1444.

Gundersen, H. J. G. and Østerby, R. 1981. Optimizing sampling efficiency of sterological studies in biology: or ”Do more less well”. Journal of Microscopy 121, 65-73.

Gundersen, H. J.G., Bendtsen, T. F., Korbo, L., Marcussen, N., Møller, A., Nielsen, K., Nyengaard, J. R., Pakkenberg, B., Sørensen, F. B., Vesterby, A. and West, M. J. 1988. Some new, simple and effective stereological methods and their use in pathological research and diagnostics. APMIS 96, 379-394.

Hamre, K. 2006. Nutrition in cod (Gadus morhua) larvae and juveniles. ICES Journal of Marine Science 63, 267-274.

Hoehne, K. 1999. Lipid digestive enzymes in developing larvae of the Atlantic cod (Gadus morhua) and turbot (Scophthalmus maximus). PhD thesis, University of Karlsruhe/Norwegian University of Science and Technology. Shaker Verlag. 111pp.

Hoehne- Reitan, K. and Kjørsvik, E. 2004. Functional development of the liver and exocrine pancreas. American Fisheries Society Symposium 40, 9-36.

Howard, C. V. and Reed, M. G. 1998. Unbiased Stereology- Three-dimensional measurement in microscopy. Bios Scientific Publishers. Springer-Verlag. New York.

Høvde, G., Wold, P.-A, and Kjørsvik. Submitted. Cod (Gadus morhua) larval liver development and effects of early weaning for formulated diets.

Izquierdo, M. S., Socorro, J., Arantzamendi, L., and Hernandez-Cruz, C. M. 2000. Recent advances in lipid nutrition in fish larvae. Fish Physiology and Biochemistry 22, 97107.

Izquerido, M. S. 2004. Nutritional requirements for finfish larvae. The Second Hatchery, Feeds and Technology Workshop, 30 september-1 October 2004, Sidney, Australia, pp.8-16. 
Kjørsvik, E. and Reiersen, A. L. 1992. Histomorphology of the early yolk-sac larvae of the Atlantic halibut (Hippoglossus hippoglossus)- an indication of the timing of functionality. Journal of Fish Biology 41, 1-19.

Kjørsvik, E., Pittman, K. and Pavlov, D., 2004. From fertilisation to the end of metamorphosis- functional development. First feeding technology. In "Culture of cold-water marine fish. Moksness, E., Kjørsvik, E. and Olsen, Y. (eds). Blackwell Publishing Ltd. pp 204-278.

Kjørsvik, E., Olsen, C., Wold, P.-A, Hoehne-Reitan, K., Cahu, C. L., Rainuzzo, J., and

Olsen, A. I. Dietary phospholipids vs. neutral lipids: Effects on skeletal development in Atlantic cod (Gadus morhua). Submitted.

Lie, Ø., Lied, E., and Lambertsen, G. 1986. Liver retention of fat and fatty acids in Cod (Gadus morhua) fed different oils. Aquaculture 59, 187-196.

MacQueen Leifson, R. 2003. Phospholipids in formulated starter feed for turbot (Scophthalmus maximus L.) and cod (Gadus morhua L.) larvae- Effects on mitochondrial membranes in turbot larvae enterocytes. Dr. Scient.-thesis. The Norwegian College of Fishery Science, University of Tromsø, Norway.

MacQueen Leifson, R., Homme, J. M., Lie, Ø., Myklebust, R. and Strøm, T. 2003. Three different lipid sources in formulated start-feeds for turbot (Scophthalums maximus L.) larvaeeffects on growth and mitochondrial alterations in eneterocytes. Aquaculture Nutrition 9, 3342.

MacQueen Leifson, R., Homme, J. M., Østensen, J. P., Lie, Ø. and Myklebust, R. 2003. Phospholipids in formulated start-feeds- Effect in turbot (Scophthalmus maximus L.) larval growth and mitochondrial alteration in enterocytes. Aquaculture Nutrition 9, 43-54.

Mayhew, T. M. 1991. The new stereological methods for interpreting functional morphology from slices of cells and organs. Experimental Physiology 76, 629-665. 
Morais, S., Caballero, M. J., Conceição, L. E. C., Izquierdo, M. S., and Dinis, M. T. 2006. Dietary neutral lipid level and source in Senegalese sole (Solea senegalesis) larvae: effect on growth, lipid metabolism and digestive capacity. Comparative Biochemistry and Physiology, Part B 1444, 57-69.

Morrison, C. M. 1993. Histology of the Atlantic Cod, Gadus morhua: An Atlas. Part FourEleutheroembryo and Larva. Canadian Special Publication of Fisheries and Aquatic Sciences 119.

O`Brien-MacDonald, K., Brown, J. and Parrish, C.C., 2006. Growth, behaviour, and digestive enzyme activity in larval Atlantic cod (Gadus morhua) in relation to rotifer lipid. ICES Journal of Marine Science 63, 275-284.

Olsen, Y. 2004. Live food technology of cold water marine fish larvae. In "Culture of coldwater marine fish. Moksness, E., Kjørsvik, E. and Olsen, Y. (eds). Blackwell. Pp 73-128.

Olsen, R. E., Myklebust, R., Kaino, T. and Ringø, E. 1999. Lipid digestibility and ultrastructural changes in the enterocyte of Arctic char (Salvelinus aplinus L.) fed linsees oil and soybean oil. Fish Physiology and Biochemistry 21, 35-44.

Olsen, R. E., Dragnes, B. T., Myklebust, R., and Ringø, E. 2003. Effect of soybean oil and soybean lecithin on intestinal lipid composition and lipid droplet accumulation of rainbow trout, Oncorhyncgus mykiss Walbaum. Fish Physiologi and Biochemistry 29, 181-192.

Rainuzzo, J., Reitan, K. I. and Olsen, Y., 1997. The significance of lipids at early stages of marine fish: a review. Aquaculture 155, 103-115.'

Ribeiro, L., Sarasquete, C., and Dinis, M. T. 1999. Histological and histochemical development of the digestive system of Solea senegalsesis, Kaup 1858. Aquaculture 171, 293308.

Salhi, M., H, Henandez-Cruz, C. M., Bessonart, M., Izquierdo, M. S. and FernandezPalacios, H. 1999. Effect of different dietary polar lipid levels and different n-3 HUFA 
content in polar lipids on gut and liver histological structure of gilthead seabrem (Sparus aurata) larvae. Aquaculture 179, 253-263.

Salvesen, I. and Vadstein, O. 1995. Surface disinfection of eggs from marine fish: evaluation of four chemicals. Aquaculture International 3,155-171.

Sargent, J. R., Tocher, D. R. and Bell, J. G. 2002. The lipids. In: Fish Nutrition. Halver, J. E and Hardy, R. W. (eds). Academic Press. pp. 182-257.

Segner, H. and Witt, U. 1990. Weaning experiments with turbot (Scophthalums maximus): electron microscopy of liver. Marine Biology 105, 353-361.

Segner, H., Rösch, R., Verreth, J. and Witt, U. 1993. Larval nutritional physiology: Studies with Clarias gariepinus, Coregonus lavaretus and Scophthalmus maximus. Journal of the World Aquaculture Society 24(2): 121-134.

Segner, H., Storch, V., Reinecke, M., Kloas, W. and Hanke, W. 1994. The development of the functional and metabolic organs in turbot, Scophthalums maximus. Marine Biology 119: 471-486.

Strüssmann, C. A. and Takashima, F. 1990. Hepatocyte nuclear size and nutrition|al condition of larval pejerry, Odontesthes bonariensis (Cuvier et Valenciennes). Journal of Fish Biology 36, 59-65.

Weibel, E. R and Gomez, D. M. 1962. A principle for counting tissue structures on random sections. Journal of Applied Physiology 17(2): 343-348.

Weibel, E. R., Stäubli, W., Gnägi, H. R. and Hess, F. A. 1969. Correlated morphometric and biochemical studies on the liver cell. The Journal of Cell Biology 42: 68-91.

Wold, P.-A, Hoehne-Reitan, K., Cahu, C.L., Zambonino Infante, J. L., Rainuzzo, J., and Kjørsvik, E. 2007. Phospholipids vs. neutral lipids: Effects on digestive enzymes in Atlantic cod (Gadus morhua) larvae. Aquaculture 272: 502-513. 
Wold, P.-A, Hoehne-Reitan, K., Rainuzzo, J. and Kjørsvik, E. 2008. Gut development in larval cod (Gadus morhua). Journal of Fish Biology 72: 1637-1658.

Zambonino Infante, J. L and Cahu, C. L. 2001. Ontogeny of the gastrointestinal tract of marine fish larvae. Comparative Biochemistry and Physiology Part C 130, 477-487. 
Tables and figures:

Table 1: Composition of experimental diets (\%).

\begin{tabular}{|c|c|c|c|}
\hline $\begin{array}{l}\text { Diet } \\
\text { Ingredients }^{\mathrm{a}} \\
\end{array}$ & PL3 & PL1 & NL1 \\
\hline \multicolumn{4}{|c|}{ Lipid ingredients (g/100g) } \\
\hline Cod liver oil & 0 & 0 & 7 \\
\hline Marine lecithin ${ }^{\mathrm{b}}$ & 14 & 7 & 0 \\
\hline Soybean lecithin ${ }^{\mathrm{c}}$ & 7 & 14 & 14 \\
\hline \multicolumn{4}{|c|}{ Proximate composition (\%) } \\
\hline Proteins (N x 6.25) & 61.5 & 58.3 & 57.7 \\
\hline Lipids & 16.1 & 16.4 & 17.9 \\
\hline Phospholipids & 12.5 & 12.4 & 10.7 \\
\hline EPA + DHA in PL & 2.3 & 1.1 & 0.3 \\
\hline Neutral lipids & 3.7 & 4.4 & 6.8 \\
\hline EPA + DHA in NL & 0.3 & 0.3 & 1.3 \\
\hline Ash & 17.4 & 17.5 & 17.4 \\
\hline Moisture & 7.5 & 7.1 & 7.2 \\
\hline Energy $^{\mathrm{d}}$ & 1634 & 1592 & 1639 \\
\hline
\end{tabular}

${ }^{a}$ All dietary ingredients were commercially available. Fish meal (La Lorientaise, Lorient, France), hydrolyzed fish meal (CPSP, Soluble Fish Protein Concentrate; Sopropêche, Boulogne sur Mer, France), cod liver oil (La Lorientaise), marine lecithin (LC60, Phosphomins ${ }^{\text {TM}}$; Phosphotech, Saint Herblain, France).

${ }^{\mathrm{b}}$ Contains 60\% phospholipids (with 45\% PC, 20\% PE, 16\% PI), 5\% TAG, 15\% cholesterol, and 1 mg/g natural tocopherols as antioxidant. ${ }^{\mathrm{c} C o n t a i n s}$ 95\% phospholipids (with 26\% PC, 20\% PE, and 14\% PI).

${ }^{\mathrm{d}}$ Calculated as: fat x $37.7 \mathrm{~J} / \mathrm{kg}$; protein x $16.7 \mathrm{~J} / \mathrm{kg}$.

Table 2. Mean larval daily weight increase between 35 and 45 dph larval dry weight (mean \pm standard errors, $n=3$ replicate tanks -15 larvae per tank) and standard length $(n=5)$ on 45 dph. Different letters denote significant differences within the same feature measured.

PL3

PL1

NL1

\begin{tabular}{l|c|c|c}
\hline Larval dry weight (mg) & $2.67 \pm 0.39 \mathrm{a}$ & $2.75 \pm 0.52 \mathrm{a}$ & $2.23 \pm 0.16 \mathrm{~b}$ \\
\hline Larval standard length & & & \\
$\mathbf{( m m )}$ & $14.8 \pm 0.5$ & $14.1 \pm 0.8$ & $13.6 \pm 0.6$ \\
\hline Daily weight increase (\% & & & $11.4 \pm 0.6$ \\
DW/day) & $13.3 \pm 2.2$ & $16.2 \pm 2.1$ & \\
\hline
\end{tabular}


Table 3: Data of stereological estimates of the intestine in 45-days-old cod larvae $(n=5$, means \pm standard errors).

\begin{tabular}{|c|c|c|c|}
\hline Diet/measurement & PL3 & PL1 & NL1 \\
\hline $\begin{array}{l}\text { Intestinal length } \\
\text { (mm) }\end{array}$ & $6.01 \pm 0.49$ & $5.21 \pm 0.40$ & $4.78 \pm 0.52$ \\
\hline $\begin{array}{l}\text { Intestinal volume } \\
\left(\mathrm{mm}^{3}\right)\end{array}$ & $0.90 \pm 0.12$ & $0.74 \pm 0.09$ & $0.64 \pm 0.13$ \\
\hline $\begin{array}{l}\text { Enterocyte nuclei } \\
\text { size }\left(\mu^{3}\right)\end{array}$ & $65.2 \pm 3.6$ & $78.9 \pm 5.3$ & $71.6 \pm 6.8$ \\
\hline $\begin{array}{l}\text { Mitochondrial size } \\
\left(\mu^{3}\right)\end{array}$ & $0.81 \pm 0.11$ & $0.99 \pm 0.16$ & $0.68 \pm 0.07$ \\
\hline $\begin{array}{l}\text { Lipid volume } \\
\text { density (\%) }\end{array}$ & $1.02 \pm 0.5$ & $0.76 \pm 0.3$ & $0.48 \pm 0.3$ \\
\hline
\end{tabular}

Table 4: Data of stereological estimates of the liver in 45-days-old cod larvae $(n=5$, means \pm standard errors).

\begin{tabular}{|c|c|c|c|}
\hline Diet/measurement & PL3 & PL1 & NL1 \\
\hline Liver volume $\left(\mathrm{mm}^{3}\right)$ & $0.32 \pm 0.004$ & $0.33 \pm 0.67$ & $0.28 \pm 0.05$ \\
\hline $\begin{array}{l}\text { Hepatocyte size } \\
\left({\left.\mu \mathrm{m}^{3}\right)}^{3}\right.\end{array}$ & $1861 \pm 84 a$ & $1800 \pm 42 a$ & $1589 \pm 23 b$ \\
\hline Hepatocytes /liver & $167269 \pm 20822$ & $182489 \pm 37757$ & $178915 \pm 29131$ \\
\hline $\begin{array}{l}\text { Hepatocyte nuclei } \\
\text { size }\left(\mu^{3}\right)\end{array}$ & $66.5 \pm 3.5 a$ & $65.0 \pm 3.1 \mathrm{a}$ & $55.2 \pm 1.4 \mathrm{~b}$ \\
\hline $\begin{array}{l}\text { Mitochondrial size } \\
\left(\mu^{3}\right)\end{array}$ & $1.94 \pm 0.15$ & $1.98 \pm 0.30$ & $2.43 \pm 0.30$ \\
\hline $\begin{array}{l}\text { Lipid volume } \\
\text { density (\%) }\end{array}$ & $1.4 \pm 1.1 \mathrm{a}$ & $2.14 \pm 0.4 \mathrm{ab}$ & $4.38 \pm 1.3 b$ \\
\hline $\begin{array}{l}\text { Glycogen volume } \\
\text { density (\%) }\end{array}$ & $1.6 \pm 0.5$ & $1.0 \pm 0.3$ & $1.0 \pm 0.4$ \\
\hline
\end{tabular}


Table 5: Data of stereological estimates of the pancreas in 45-days-old cod larvae $(n=5$, means \pm standard errors).

\begin{tabular}{l|c|c|c} 
Diet/measurement & PL3 & PL1 & NL1 \\
\hline $\begin{array}{l}\text { Pancreatic nuclei } \\
\text { size }\left(\boldsymbol{\mu m}^{3}\right)\end{array}$ & $33.1 \pm 2.1$ & $37.1 \pm 2.5$ & $32.0 \pm 2.5$ \\
\hline $\begin{array}{l}\text { Mitochondrial } \\
\text { volume density (\%) }\end{array}$ & $5.5 \pm 0.62$ & $7.38 \pm 1.15$ & $4.73 \pm 0.70$ \\
\hline $\begin{array}{l}\text { Mitochondrial size } \\
\left(\boldsymbol{\mu m}^{3}\right)\end{array}$ & $2.70 \pm 0.59$ & $2.23 \pm 0.54$ & $1.67 \pm 0.16$ \\
\hline $\begin{array}{l}\text { Zymogen volume } \\
\text { density (\%) }\end{array}$ & $2.65 \pm 0.36$ & $2.74 \pm 0.91$ & $2.73 \pm 0.39$
\end{tabular}

\section{Segments}

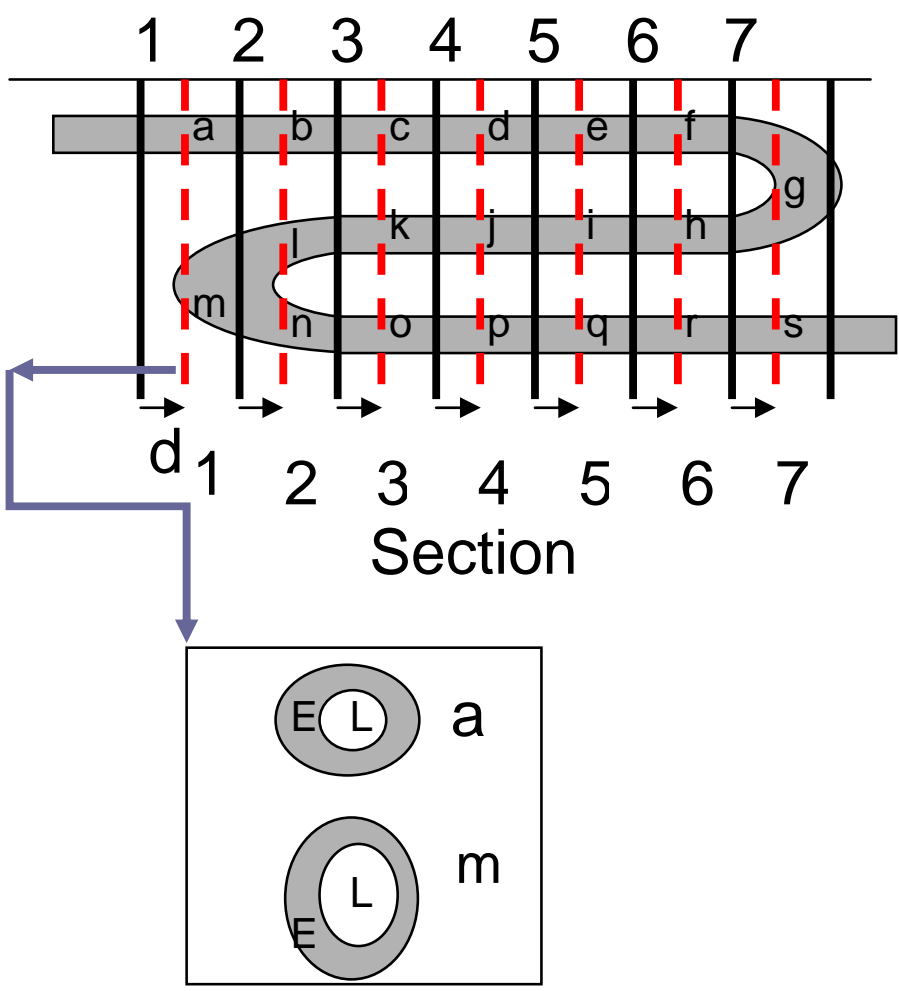

Figure 1: Random sampling scheme for sectioning of cod larval intestine with s-shape on 45 dph. Dissected intestines were divided into 7 segments of equal length (solid lines). The area to be sectioned (broken lines) was determined by a random number table to be at the distance $\mathrm{d}$ from the front of the segment. The next section to be studied was in the distance $d$ in the subsequent section. Each section contained 1 to 3 gut regions, depending of the midgut shape, 
which are denoted by letters related to their ranking order in the entire midgut. Enlarged illustration of section 1 (from segment 1) shows as an example that this section contains the first (a) and the thirteenth (m) region of the midgut. Epithelium tissue (E- grey colour) was used for the estimations of midgut volume, without using the lumen (L- white colour).

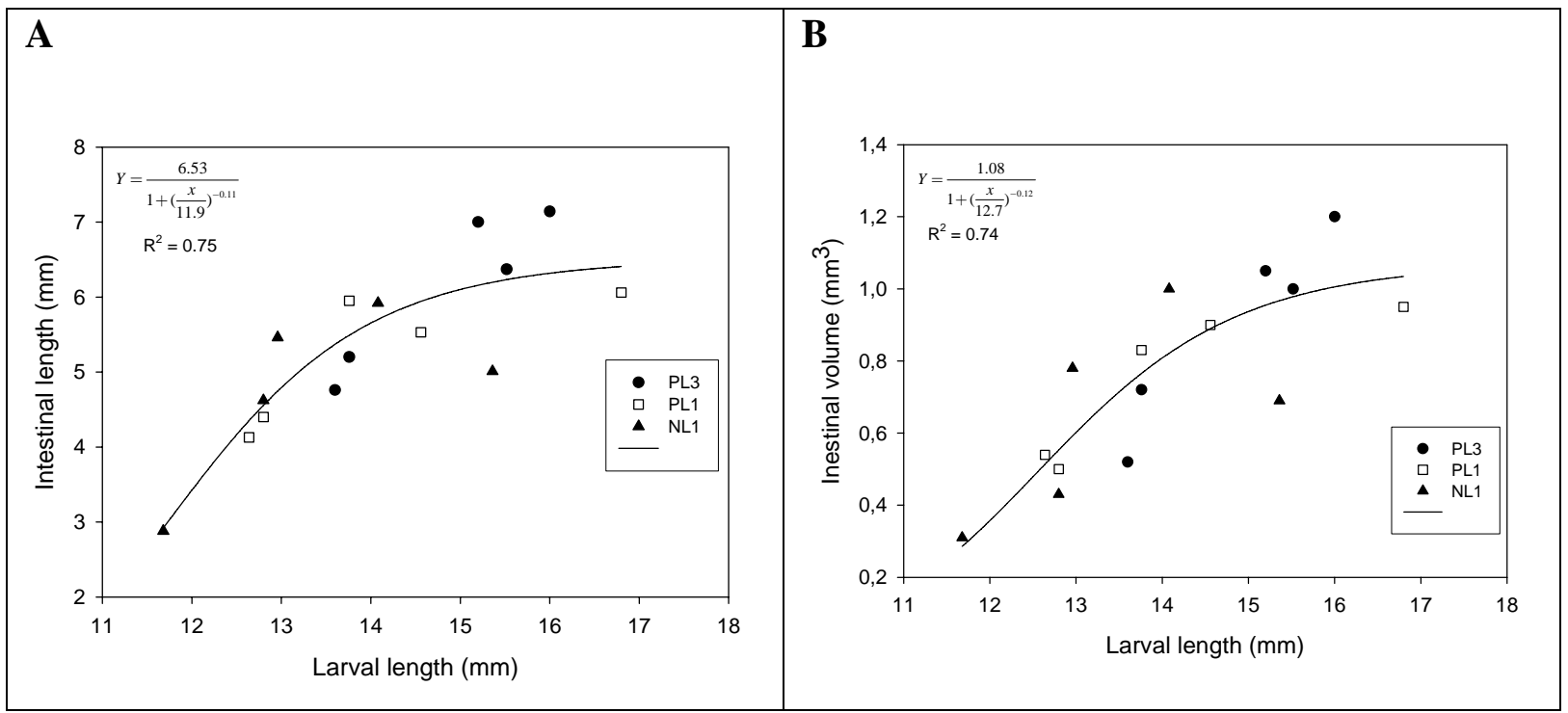

Figure 2. A. Positive sigmoid regression between intestinal length (mm) and larval standard length (mm) in 45-days-old cod larvae fed three isolipidic diets, $n=5$ for each dietary treatment. B. Positive sigmoid regression between intestinal volume $\left(\mathrm{mm}^{3}\right)$ and larval standard length (mm) in 45-days-old cod larvae fed three isolipidic diets showing sigmoid regression. $\mathrm{n}=5$ for each dietary treatment. 
A

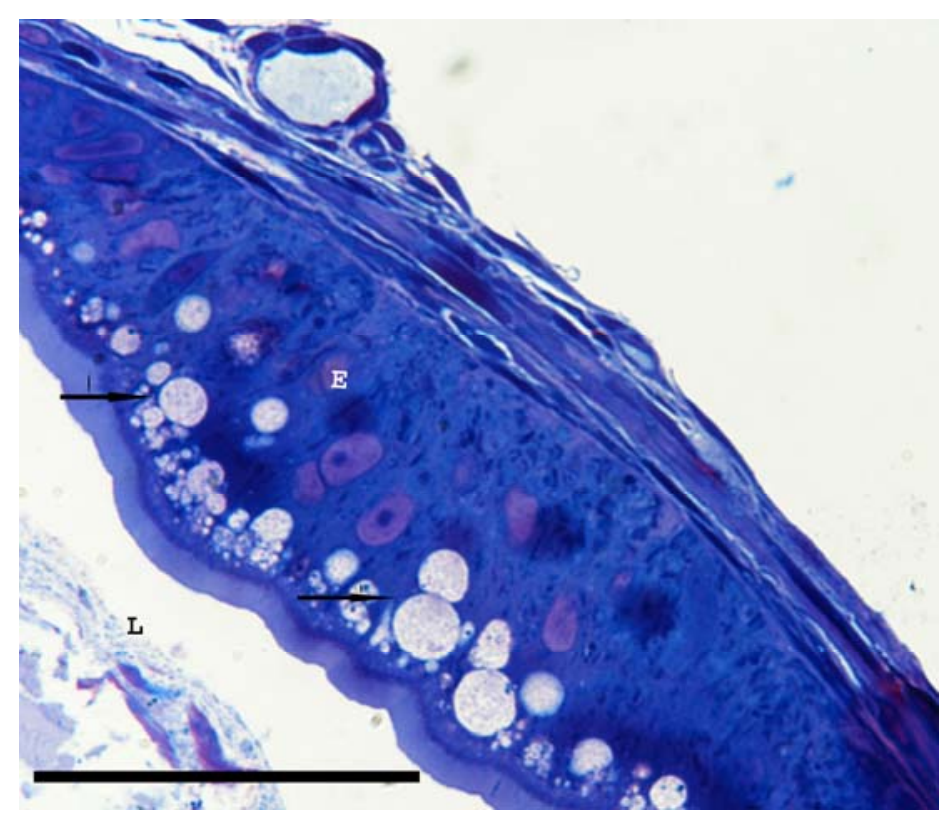

B

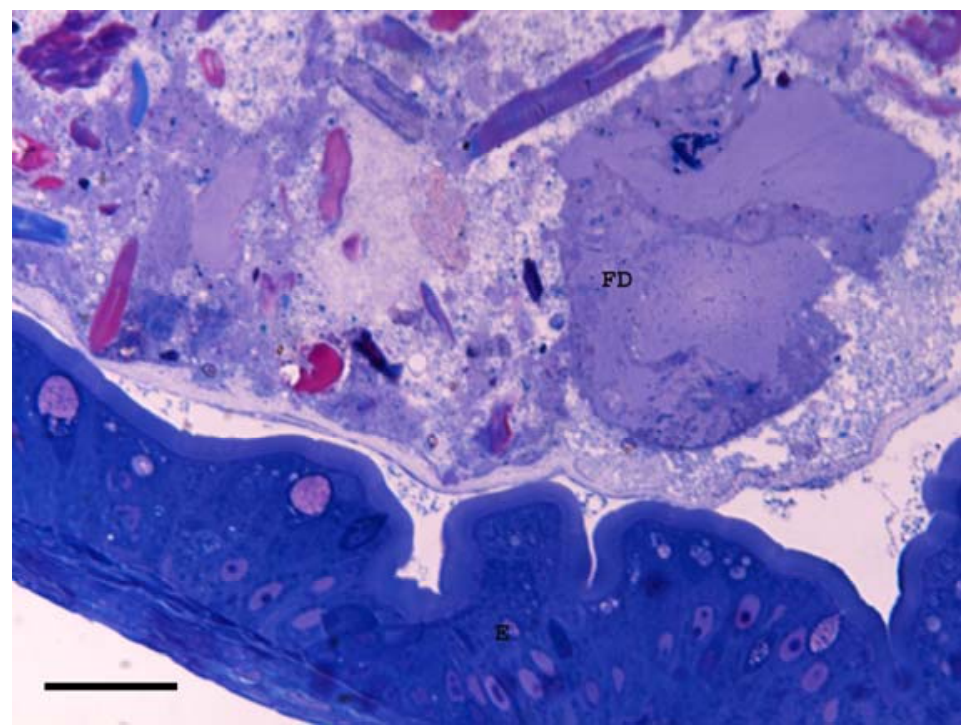

Figure 3. A. Lipid vacuolisation (arrows) observed locally in the midgut epithelium tissue (E) in 45-days old cod larvae fed the PL3-diet. $\mathrm{L}=$ lumen, $\mathrm{E}=$ epithelium tissue. Scale bar $30 \mu \mathrm{m}$. B. Ingested formulated diet pellet (FD) in the foregut of a 45-days-old cod larvae fed the PL3diet. Scale bar $30 \mu \mathrm{m}$. 
A

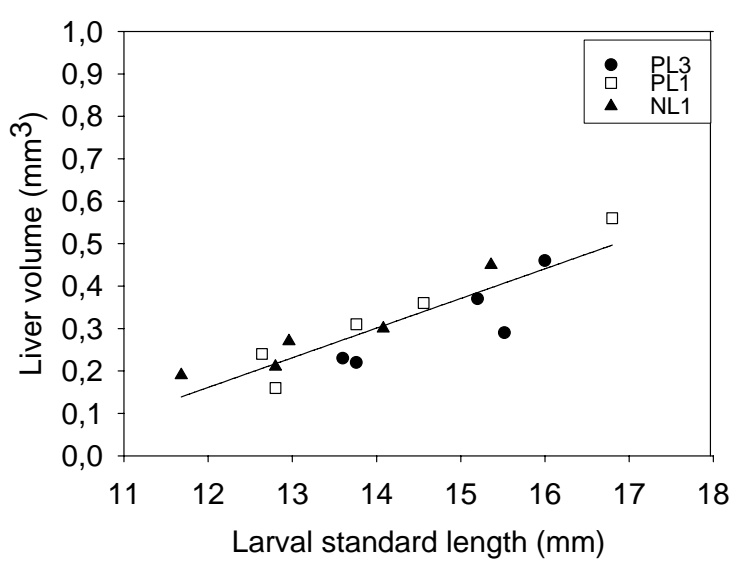

B

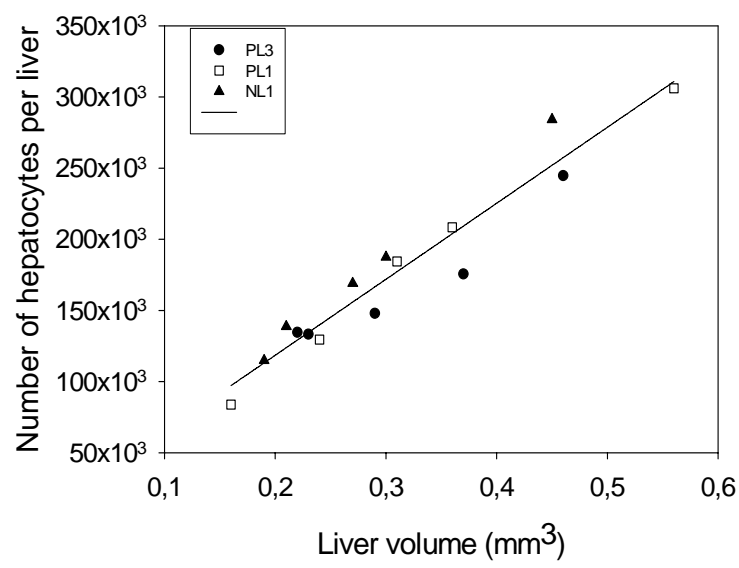

Figure 4. A. Positive linear regression between liver volume $\left(\mathrm{mm}^{3}\right)$ and larval standard length (mm) in 45-days-old cod larvae fed three isolipidic diets, $\mathrm{Y}=0.68+0.07 \mathrm{x}, \mathrm{R}^{2}=0.80$. $\mathrm{n}=5$ for each dietary treatment. B. Positive linear regression between number of hepatocytes and liver volume $\left(\mu \mathrm{m}^{3}\right)$ in 45-days-old cod larvae, $\mathrm{Y}=0.0005 \mathrm{x}-11743, \mathrm{R}^{2}=0.93 \mathrm{n}=5$ for each dietary treatment. 
A

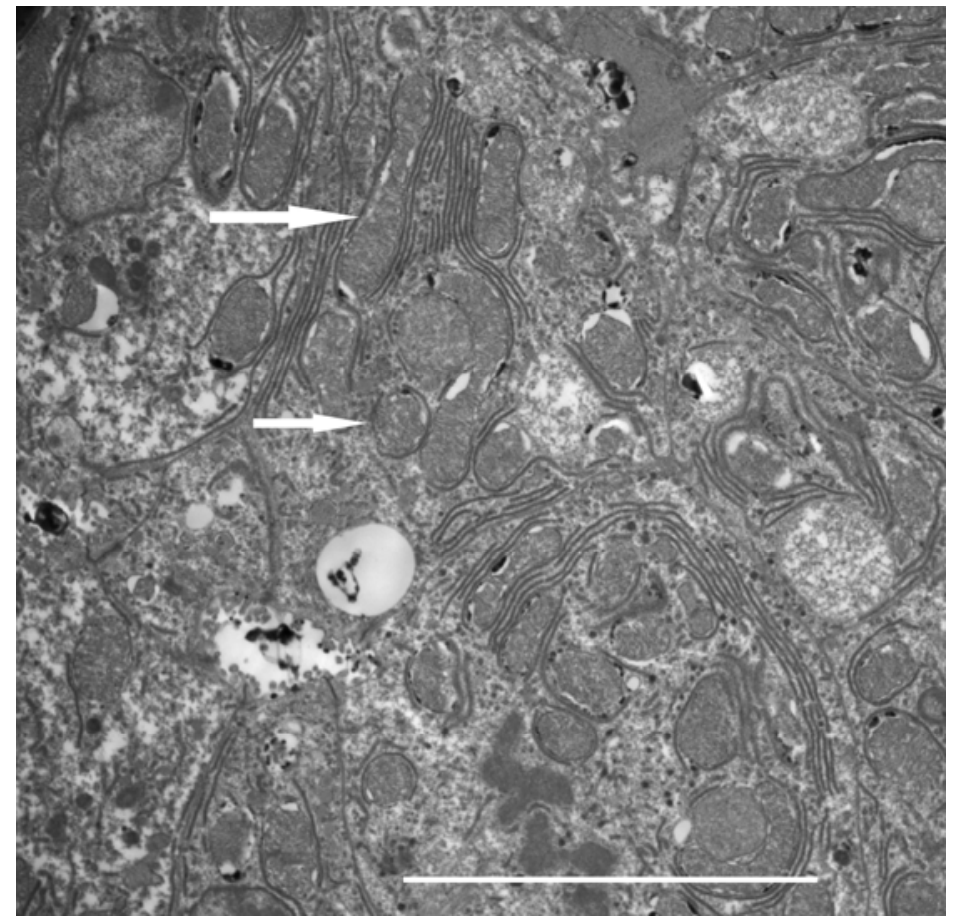

B

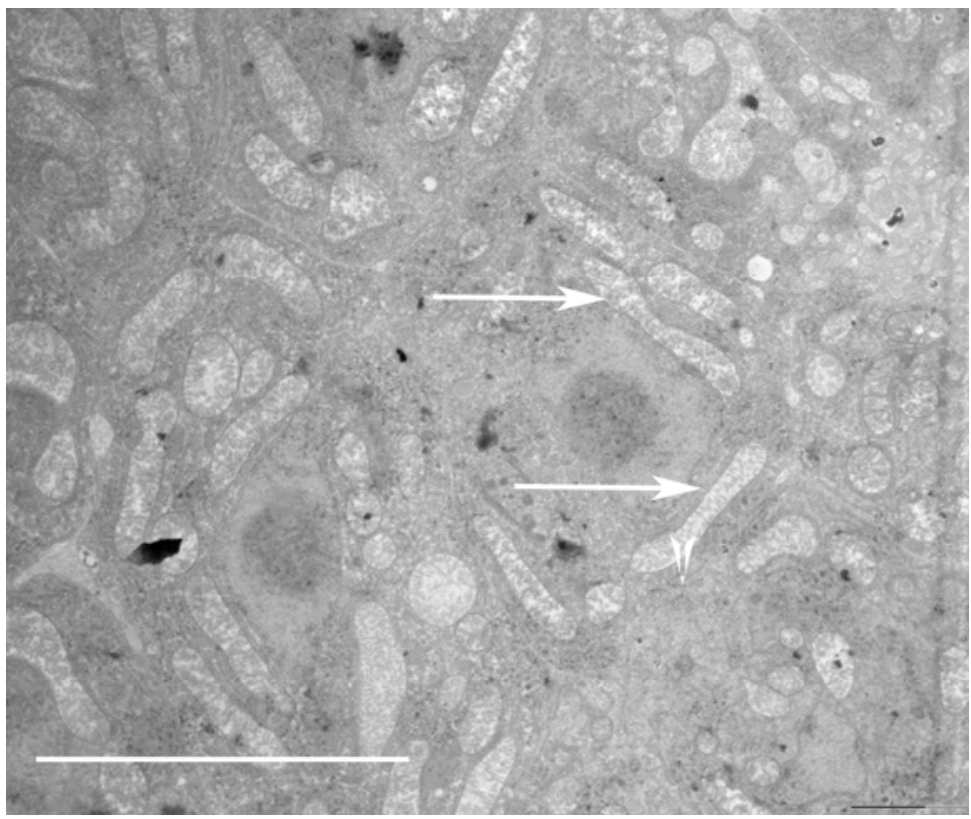

Figure 5. Micrographs showing hepatocyte mitochondria (arrows) in 45-days-old cod larvae. Magnifications 5000X. Scale bar 10 $\mu \mathrm{m}$. A. Mitochondria in PL3-larvae had a dense intermembranous matrix. B. Mitochondria in NL1-larvae were more transparent and had a less dense intermembranous matrix. 


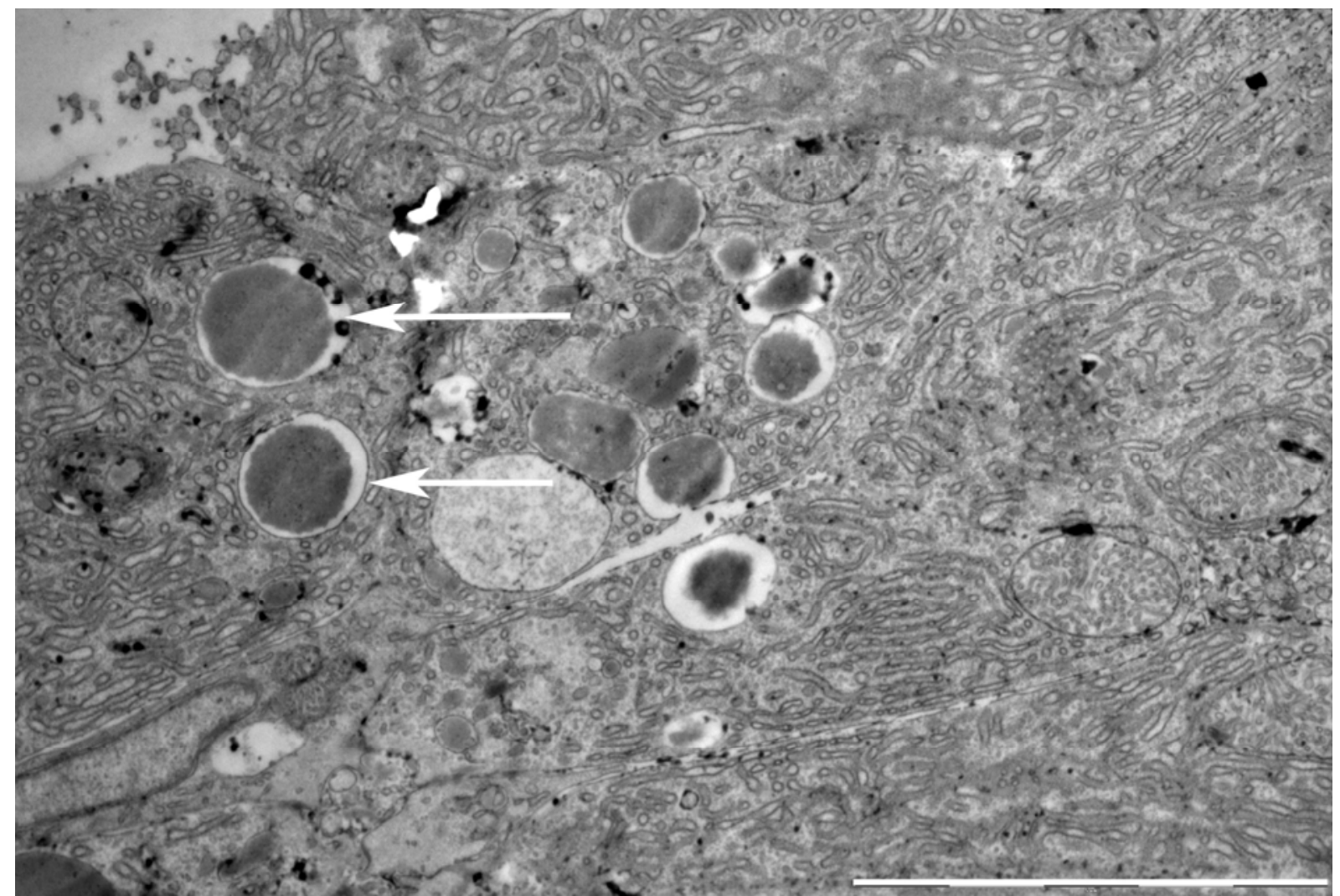

Figure 6. Pancreatic tissue with zymogene granulae (arrows) in 45 dph larvae fed the PL3diet. Magnifications 10 000X. Scale bar $5 \mu \mathrm{m}$. 
A

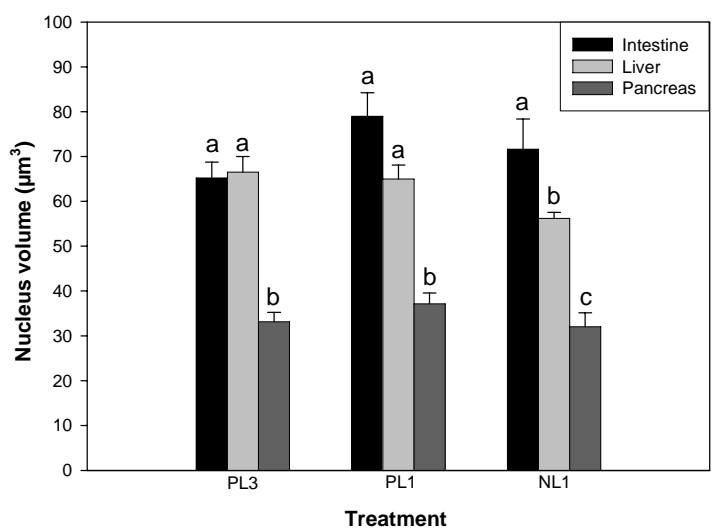

B

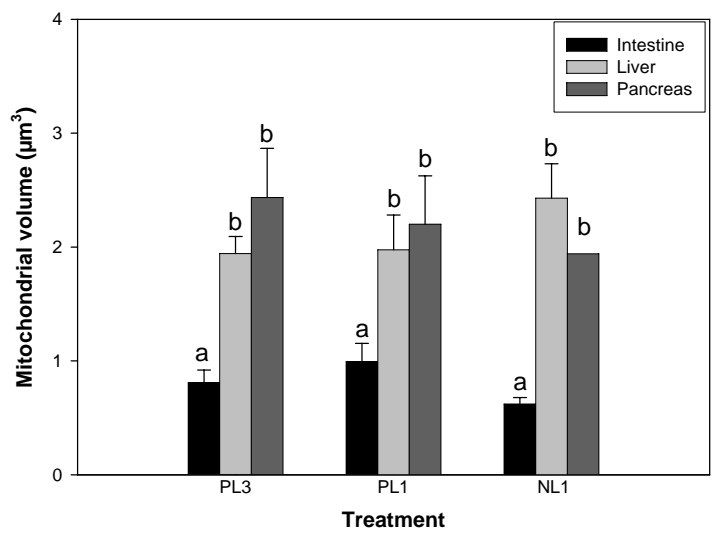

Figure 7. Estimates of nuclei (A) and mitochondrial (B) size in the intestine, liver and pancreas from the different dietary treatments ( $n=5$ larvae, means \pm standard errors). Letters denote significant differences between organs within one dietary treatment. 